\title{
Health Status of Marginalized Groups in India
}

\author{
Zulufkar Ahmad Khanday", Mohammad Akram
}

Department of Sociology and Social Work, Aligarh Muslim University Aligarh, Uttar Pradesh, 202002, India

\begin{abstract}
Marginalization is a symbol that refers to processes by which individuals or groups are kept at or pushed beyond the edges of society. The term outsiders may be used to refer to those individuals or groups who are marg inalized. This research paper is an endeavour to study the health status of marginalised groups and commun ities - women, children, scheduled castes, scheduled tribes, persons with disabilities, mig rants and also the health status of aged in India. The paper also aims to highlight the discrimination and exploitation of these marginalised groups especially in terms of their health. Further, study is carried out about how the rights of these marginalised groups are violated within the society. In India there are multiple socio-economic disadvantages that members of particular groups experience which limits their access to health and healthcare. Some of the prominent factors on the basis of which individuals belonging to marg inalised groups are discriminated in India, i.e., structural factors, age, disability, mobility and stigma that act as barriers to health and healthcare. Sometimes each group faces multiple barriers due to their multiple identities. For example, in a patriarchal society, disabled women face double discrimination of being a women and being disabled. Besides this there are certain groups in Indian society that are subject to discriminatory treatment and feel marginalized. They need special attention to avoid exploitation. The rights of disabled and migrants have been violated and sometimes they are discriminated and medical personnel are not ready to treat them because they are unable to pay such a huge amount for med icines. No proper attention has been given towards their health condition. Finally it can be said that the health status of these marginalised groups in India are very poor as compared to other sections of population. This paper is based on the secondary sources such as reports, journals, census, books, articles and online sources.
\end{abstract}

Keywords Women, Scheduled Castes, Scheduled Tribes, Migrants, Persons with Disabilities and Aged

\section{Introduction}

The concept of marginality was first introduced by Robert Park (1928). Marg inalization is a symbol that refers to processes by which individuals or groups are kept at or pushed beyond the edges of society. The term outsiders may be used to refer to those individuals or groups who are marginalized[1]. The Encyclopaedia of Public Health defines marginalization as, "to be marginalized is to be placed in the margins and thus excluded from the privilege and power found at the centre"[2]. Ghana S. Gurung and Michael Kollmair mention that the concept of marginality is generally used to analyse socioeconomic, political, and cultural spheres, where disadvantaged people struggle to gain access to resources and full participation in social life. In other words, marginalized people might be socially, economically, politically and legally ignored, excluded or neglected and therefore vulnerable to livelihood change[2].

A great majority of people in the developing nations are under the line of poverty. They are deprived of adequate

\footnotetext{
* Corresponding author:

k.zulufkar.amu@gmail.com (Zulufkar Ahmad Khanday)

Published online at http://journal.sapub.org/ijas

Copyright (C) 2012 Scientific \& Academic Publishing. All Rights reserved
}

access in the basic needs of life such as health, education, housing, food, security, employment, justice and equity. Chandrima Chatterjee and Gunjan Sheoran[3] mention that the issues of sustainable livelihood, social and political participation of the vulnerable groups exists as the major problem in these developing nations- particularly in India. Govern ments have failed to guarantee people's rights in the implementation level. People who belong to the vulnerable groups are unable to acquire and use their rights. In this background, the International Covenant on Civil and Political Rights (ICCPR) and the International Covenant on Economic, Social and Cultural Rights (ICESCR),[4],[5] have guaranteed the rights to sustainable live lihood, social, political and economic development for all especially those disadvantaged. Many countries have ratified thesecovenants. In the year 2000, the committee on economic, social and cultural rights offered explicit details of all the possible instances of violation that individuals and groups within a nation are likely to suffer from besides listing out obligations for the state to protect and fulfil the right of everyone to the enjoyment of the highest attainable standard of physical and mental health through the general comment 14. Despite international commitment, individuals and groups experience differential access to food, education and health in India. The health rights of vulnerable groups 
remain detached from the state systems i.e. policy, programme and practice[6].

Human rights are universally applicable to all. The process of identifying vulnerable groups within the health and human right generated from the pressing reality on the ground that stemmed from the fact that there are certain groups who are vulnerable and marginalized lacking full enjoyment of a wide range of hu man rights, including rights to political participation, health and education. Vulnerability within the right to health framework means deprivation of certain individuals and groups whose rights have been violated from the exercising agency[7]. Certain groups in the society often encounter discriminatory treatment and need special attention to avoid potential exploitation. This population constitutes what is referred to as vulnerable or what nova-days called marginalized Groups. Vulnerable groups are disadvantaged as compared to others main ly on highest attainable standards of health. Vulnerable groups are disadvantaged as compared to others mainly on account of their reduced access to medical services and the underlying determinants of health such as safe and potable drinking water, nutrition, housing, sanitation etc. For example, persons with disabilities often don't get employment or adequate treatment or people living with HIV/AIDS, face various forms of discrimination that affects their health and reduces their access to health services [3].

\section{Objectives}

The present paper is based on secondary sources such as books, reports, journals, committees, articles, papers and other different sources of internet. The objectives of the present paper are to study the health status of marginalised groups- women's, children's, scheduled castes, scheduled tribes, persons with disabilities, migrants and also the health status of aged in India; the violation of their rights; the double exploitation which women's face in their home and at the work place and also to study how the different factors affecting the health of the marginalised groups.

\section{Results and Discussion}

In India there are multiple socio-economic disadvantages that members of particular groups experience which limits their access to health and healthcare. Chandrima Chatterjee and Gunjan Sheoran, "Reference[3]" argues that there are the some of the prominent factors on the basis of which individuals belonging to marginalised groups are discriminated in India, i.e., structural factors, age, disability, mobility, stigma and discrimination that act as barriers to health and healthcare. The vulnerable groups that face discrimination include women, Scheduled Castes (SC's), Scheduled Tribes (ST,s), children, aged, disabled, poor migrants, people living with HIV/AIDS and sexual minorities "Reference[3]". So metimes each group faces multiple barriers due to their multiple identities. For example, in a patriarchal society, disabled women face double discrimination of being a wo men and being disabled "Reference[3]".

\section{Structural Discrimination}

In India norms and cultural practices are rooted in a highly patriarchal social order where wo men are expected to adhere to strict gender roles and they are affected by more health problems as compared to men. The prevalence of poverty and economic dependence among wo men, their experience of violence, gender bias in the health system and society at large, discrimination on the grounds of race or other factors, the limited power and their lack of influence in decision-making are social realities have an adverse impact on their health of women's. So women face particular health issues and particular forms of discrimination, with some groups, including internally displaced wo men, wo men in slums and sub-urban settings, indigenous and rural women, women with disabilities or women living with HIV/AIDS, facing multiple forms of discrimination, barriers and marg inalization in addition to gender discrimination[6].

\section{Women}

Chandrima Chatterjee and Gunjan Sheoran "Reference [3]"mentions that in Indian societies women face double discrimination being members of specific caste, class or ethnic group apart from experiencing gendered vulnerabilities. Women have low status as compared to men in Indian society. They have little control on the resources and on important decisions related to their lives. The early marriage and childbearing, miscarriages, multiple pregnancies create serious health hazards for women's [8]. About 28 per cent of girls in India get married below the legal age and experience pregnancy "Reference[3]". These have serious repercussions on the health of women. It has been noted earlier that women in India who are uneducated and poor are the most vulnerable to disease and ill health during their lifetime[9]. They experience different types of mortality including reproductive problems, aches, pain and injuries; weakness, nutritional problems, fever, respiratory problems; problems in the gastro intestinal tract; skin, eye and ear problems and a residual category of 'other' problems[10]. The institutional delivery is lowest among women from the lower economic class as against those fro $m$ the higher class "Reference[3]".

In recent years, studies on domestic violence in the country have systematically debunked the myth of the home as a safe haven. Violence against women in India cuts across caste, class and other divides. Nationally it is estimated that $21 \%$ of wo men have experienced beatings or physical mistreatment 'by husband, in laws or other persons since the age of fifteen (IIPS and ORC Macro, 2000) [8]. 
B. L. Nagda, "Reference[8]" mentions that violence against women includes violence that occurs within the family or within the community in general. The main factor of violence is the inequality between men and women and discrimination faced by women in their day-to-day life. Now-a-days the violence against women can be conceptualised as an issue of power and social control over women. Nagda (2001) conducted a community survey of 230 women in tribal areas of Rajasthan and found that among tribal women, 62 percent women were physically beaten by their husbands at least once a month. Majority $(83 \%)$ of females reported was verbally abused by their husbands, in-laws and other family members at least once a week. About 39 percent women suffered mental and physical tortures in the family. Sometimes in extreme forms of violence the victim may be killed. Further, Nagda (2001) reported that more than two-thirds of the tribal wo men were abused by their husband, having fights regularly in evening and being insulted, taunted and criticised. Despite of this the majority of wives who suffered in domestic violence are als o suffering in many health hazards like reproductive tract infection/STD, depression anaemia, blood pressure, somatic disorders and broken family etc. Thus, violence against women's has a major impact on women's physical and mental health and effects their sexual and reproductive health, unwanted pregnancies, the transmission of STD / $\mathrm{HIV}$, forced abortion and finally violence affected women's can have fatal consequences, including suicide, homicide, and maternal mortality. Women's face violence that significant impact on their physical and mental health. During infancy and growing years a girl child faces different forms of violence like infanticide, neglect of nutrition needs, education and healthcare.

In Rajasthan and particularly in the tribes of the state, health status of women is very poor and the number of pregnancy related deaths in the tribal areas is higher in the state. The maternal mortality rate in the state is higher in comparison to the country as a whole. Malnutrition is widespread among the tribal girls and women. In reality tribal women's observe unequal access to basic health services. The terrible poverty, lack of nutritious food, and safe drinking water, lack of sanitation and hygienic accommodation, hostile life created problem of health among the wo men in tribal areas "Reference[8]".

Thus the violence against women is a widespread cause of physical and psychological harm or suffering among wo men, as well as a violation of their right to health. The committee on the elimination of discrimination against wo men requires states to, among other things, enact and enforce laws and policies that protect women and girls from violence and abuse and provide for appropriate physical and mental health services; in connection with pregnancy, childbirth and the post-natal period, including family planning and emergency obstetric care. Health-care workers should also be trained to detect and manage the health consequences of violence against women, while female genital mutilation should be prohibited[11].

Sexual and reproductive health is also a key aspect of women's right to health. The most productive years of a woman's life are the reproductive years. The absence of maternity entitlements often means that a woman worker has to leave her job to have a child. With the near absence of any effective primary health care system in the country, most women are forced to have children at home without any medical care. A majority of the women and their families in India are unable to bear the burden of hospitalization costs. Even when they opt for hospitalization, additional medical expenses and loss of employment makes women economically vulnerable. Absence of maternity entitlements also means that a wo man is unable to take care of her nutritional needs before and after the pregnancy and get adequate rest, and is compelled to start working soon after child birth. Social security for the unorganised workers must ensure that maternity entitlements including paid leave are available to all women, whether employed or not, in terms of hospital and medical expenses and these maternity entitlements include paid maternity leave of at least 12 weeks [12].

The absence of child care provisions means that the burden of work on women is increased tremendously, affecting their health and work participation. For women workers, their own health and ability to work is usually the only resource they can fall back upon. They are the most vulnerable in this regard because their health and nutrition needs are the lowest priority within the family. Women in the poorest households are the least likely to receive medical attention "Reference[12]". Besides this, the discrimination against the girl child is systematic and pervasive enough to manifest in many demographic measures for the country. For the country as a whole as well as its rural areas, the infant mortality rate is higher for females in comparison to that for males. This infant mortality rate is slightly in favour of females in the urban areas of the country (as a whole) but, urban India is marked by greater access to abortion services and unwanted girl children often get eliminated before birth "Reference[10]".

\section{ST's and SC's}

Marginalization of certain groups or classes occurs in most societies including developed countries and perhaps it is more pronounced in underdeveloped countries. In the Indian context, caste may be considered broadly as a proxy for socio-economic status and poverty. In the identification of the poor, scheduled caste and scheduled tribes and in some cases the other backward castes are considered as socially disadvantaged groups and such groups have a higher probability of living under adverse conditions and poverty. The health status and utilization patterns of such groups give an indication of their social exclusion as well as an idea of the linkages between poverty and health[13].

Caste in Indian society is a particular form of social 
inequality that involves a hierarchy of groups ranked in terms of ritual purity where members who belong to a particular group or stratum share some awareness of common interest and a common identity. Structurally the lower castes were economically dependent on the higher castes for existence. The Scheduled Caste (lower castes) remained economically dependent, politically powerless and culturally subjugated to the upper caste. This kind dominance of higher castes on the lower castes effects their overall lifestyle and access to food, education and health [14].

In a caste-dominated country like India; Dalits who comprises more than one-sixth of the Indian population (160 million approx.), stand as a community whose human rights have been severely violated. Structural discrimination against these groups takes place in the form of physical, psychological, emotional and cultural abuse which receives legitimacy from the social structure and the social system. Physical segregation of their settlements is common in the villages forcing them to live in the most unhygienic and inhabitable conditions. All these factors affect their health status, access to healthcare, and quality of health service received. The scavenger community among the Dalits are vulnerable to stress and diseases with reduced access to healthcare[3]. Studies on nature of exclusion and discrimination faced by Dalit children in using public health services in rural areas are very limited; however there is indirect evidence which is reflected in indicators related to health. Mortality, for example, is an important indicator of health status and it is seen in India, infant mortality rate for Dalit children is high (88 per 1000) when compared to children from the 'other' social group (69 per 1000)[15]. Structural discrimination directly impedes equal access to health services by way of exclusion. The negative attitude of the health professionals towards these groups also acts as a barrier to receiving quality healthcare from the health system[3].

The scheduled tribes like the scheduled castes face structural discrimination within the Indian society. Un like the scheduled castes, the scheduled tribes are a product of marginalization based on ethnicity. B.V. Babu and Y.S. Kusuma[16] mention that tribal's constitute about 8 percent of India's population and are spread out mostly in Madhya Pradesh, Bihar, Orissa, Andhra Pradesh, the north-east states, West Bengal, Maharashtra and Rajasthan. In India tribal's are facing various health problems like malnutrition related diseases, parasitic diseases including malaria, diarrhoea, respiratory disorders etc, and genetic disorders including sickle cell disease, thalassemia, STD and HIV/ AIDS etc. In India tribals constitute a large proportion of agricultural labourers, casual labourers, plantation labourers, industrial labourers etc. This has resulted in poverty among them, low levels of education, poor health and reduced access to healthcare services. They belong to the poorest strata of the society and have severe health problems.

The data on morbidity, mortality and other health indicators reveal that the health status of tribal population is very poor. There are many studies which indicate that communicable diseases, genetic disorders and nutritional disorders are more prevalent among tribal population in India. On one hand the communicable diseases still show higher burden while on the other non-communicable diseases are on the increase despite the poor low nutritional status and higher physical activity in their communities, thus increasing the disease burden. The situation of some of the major health problems is presented here under:

\section{Communicable Diseases}

\subsection{Malaria}

B.V. Babu and Y.S. Kusuma "Reference[16]" mentions that due to environmental situation and forest ecology, malaria is a putative endemic disease in the tribal communities since long back. Though the tribal's form only 8 percent of the total population in India, it is estimated that they contribute about 25 percent of the total number of malaria cases and about 50 per cent of P. Falciparum (cerebral malaria) cases. Malaria is prevailing among almost all dwelling tribes and continues to pose an important public health problem not only from the point of its contribution to the country's disease burden but also the economic losses associated with it (Sharma, 1998). No doubt the government has launched National Anti-Malaria Programme (NAMP) for its control and elimination; despite of that there is good number of malaria cases found in tribal population.

\subsection{Leprosy}

Leprosy is communicated through intimate and prolonged contact with the patient. It is prevalent among some tribes of Jharkhand, Chhattisgarh, Assam, Orissa, Uttar Pradesh, Tripura, Gujarat and others. The habits and practices of the tribals and the poor economic condition are responsible for it (A li, 1994). Similar reports of incidence of leprosy in tribal communities are published (Naik et al., 1999 and Rao et al., 2000) "Reference[16]".

\subsection{Tubercul osis}

This disease is reported among various tribal groups. The causative factors are nutritional deficiencies, personal hygiene environmental hygiene, environmental hygiene, overcrowding and the lack of knowledge of prevention among the tribes. Ali (1994) reported tuberculosis among the Kondh of Burlabaru of Phulbani district of Orissa and also among Kondh of Kurli of Koraput district. He reported that the poor diet and unhygienic conditions are responsible for their prevalence; and disease communication is due to the lack of ventilation and close association with the infected members "Reference[16]"

\subsection{HIV/ AIDS}


The sexually transmitted diseases are reported among tribal communities of India. Some are in the opinion that their contacts with the non-tribals are responsible to some extent for the spread of these diseases. Vyas (1980) reported the presence of syphilis and gonorrhoea among the Bhils of Rajasthan. The high level of poverty, inadequate health resources, ignorance and high-risk beliefs and practices among the tribal communities has contributed to the vulnerability of this population. As such it has created a highly susceptible population for the rapid spread of HIV/AIDS and other STDs as well. Because tribal members are forced to migrate outside of their communities in search of their work and increased wages, this may contribute to the spread of HIV/AIDS as many engage in extra-marital affairs, seek commercial sex partners or are under the threat of sexual harassment (females). While there has been limited scientific research exploring the cultural context of extra-marital sexual behaviours, it is generally noted that in these communities, extra-marital affairs are condoned and widely practised especially during periods when wo men are pregnant or nursing or during period of travel for work (Battarcharjee et al., 2000). This kind of behaviour creates a fertile ground for HIV transmission and spread. The data of Naik et al. (2005) indicate that tribal wo men are particularly vulnerable for HIV/AIDS in some tribal co mmunities, since many of them commence sexual activity at an early age and get married early as well. Also, they are in a culture that condones extra-marital sex and this exposes the women to a particular precarious situation, increasing their risk for acquiring HIV. It is evident from this study that the Indian tribal community is experiencing a latent phase that is potentially a precursor for an HIV/AIDS ep idemic. There is a high prevalence of behavioural risk factors, coupled with ignorance and inadequate health infrastructure thus creating a potential risk for rapid spread of HIV/AIDS, as well as other related diseases (Naik et al., 2005). Besides these there are many other types of communicable diseases among tribes "Reference[16]".

\section{Non-communicable Diseases}

Progressive aging of the populations, freedom from some communicable diseases and changing socio-economic situations paved the way for increase in prevalence of some non-communicable diseases that are associated with increased life expectancy and altered lifestyle. However, there is paucity of information on non-communicable diseases among tribals. Non-communicable diseases among tribals include genetic diseases, malnutrition, cardiovascular diseases etc.

\subsection{Genetic Diseases}

Genetic diseases particularly single cell disease, glucose6-phasphatedehydrogenase (G6PD) deficiency and thalasse mia are observed to occur in significantly in high frequencies amongst the tribes. It is reported that sickle cell disease frequencies are very high in certain tribes $(25 \%$ to $37 \%$ among the Soligas of Karnataka and Pardhans of Andhra Pradesh respectively). It is estimated that around three children in every thousand births among tribes of Orissa and Andhra Pradesh are suffering from sickle cell anaemia (Babu et al., 2002). It is estimated that about 13 lakhs of tribal people in India are suffering from G6PD deficiency (DST, 1990). Thalassemia contributessignificant ly for the anaemia cases in tribal population "Reference 16 ]".

\subsection{Malnutrition}

B.V. Babu and Y.S. Kusuma "Reference[16]" mentions that the provision of optimal food and nutrition is an important responsibility of the state towards its citizens. It is known from the literature that the nutritional status of not a single tribe of India can be said to be satisfactory. National institute of Nutrition (1971) and planning commission of India (1980) reported high protein-calorie malnutrition along the rice eating belt. Studies on tribes of Maharashtra and Bihar indicate the deficiency of celeries as well as proteins and essential amino acids through major signs of nutritional deficiencies (Chitre et al., 1976). Among the tribes of Assam high indices of goitre, angular stomatitis and vitamin-A deficiencies are reported (Gopalan, 1971). Similar reports on tribal malnutrition are reported from Orissa (Mahapatra and Das, 1990; Haque, 1990; Kar et al., 2002) etc. It is known from various micro studies that majority of these tribal communities are suffering from various micro-nutrient deficiency disorders (Nayak and Babu, 2003).

The nutritional problems of tribal communities are full of obscurities and very few comprehensive studies are available on dietary pattern and nutritional status of the communities. Rao (1996) concluded that nutritional status of tribes seems to be influenced by their habitat and socioeconomic condition. Due to massive deforestation, the economy of forest resource based communities and eventually their nutritional status is affected badly "Reference[16]".

B.V. Babu and Y.S Kusuma "Reference[16]" argue that it is the poverty among tribal's that makes private investments never go to tribal areas and the tribal population, who is in need of healthcare. Therefore they are unable to avail it due to poverty poor access and high cost of services. In compulsory situations, these tribal's are approaching private healthcare institutions with huge spending from their pockets. This out-of-pocket leads them to poverty and indebtedness which intern leads to illness.

Data from the NHFS-III[17][see table 1] clearly highlights the caste differentials in relation to health status. The survey documents the low levels of contraceptive use among the scheduled castes and scheduled tribes compared to forward castes/general population. Reduced access to maternal and child health care is evident with reduced levels of antenatal care, institutional deliveries and complete vaccination coverage among the lower castes. 
Stunting, wasting, underweight and anaemia in children and anaemia in adults are higher among lower castes. Similarly, neonatal, postnatal, infant and child and under-five statistics clearly show a higher mortality among SC's and ST's etc[18].

The Infant Mortality Rate (IMR) among scheduled castes is 66.4 per 1000 live births and 62.1 per 1000 per live births among the scheduled tribes. Which is more than the IMR of country (57/1000). Similarly the Under-five Mortality Rate (U-5M) also varies significantly among different socioeconomic groups in India i.e. Under-five mortality for Sc's is 88.1 per 1000 live births, 95.7 per 1000 live births and 72.8 for OBC's while as under-five mortality of the country is only 74.3. Differences in health Indicators among the various socio-economic groups are not only found IMR and U-5M But there are also profound differences in children's under-weight percentage (under the age of 5 years) among these groups i.e. the percentage of children's who are under-weight (under the age of 5 years) among ST's $(54.5 \%)$, followed by SC's $(47.9 \%)$ is quit greater than that of other general groups(33.7) and India (42.5)[19].Thus the data on these health indicators reveal that the health status of tribal population is very poor as compared to other socioeconomic groups of the country.

Table 1. Differentials in Health Stat us among Socio-Economic Groups

\begin{tabular}{|c|c|c|c|}
\hline $\begin{array}{c}\text { Social } \\
\text { Group }\end{array}$ & $\begin{array}{c}\text { Infant } \\
\text { Mortality/1, } \\
\text { 000 live } \\
\text { births }\end{array}$ & $\begin{array}{c}\text { Under-5 } \\
\text { Mortality/1, } \\
\text { 000 live } \\
\text { births }\end{array}$ & $\begin{array}{c}\text { Onderweight (Un der } \\
\text { Age 5 Years) }\end{array}$ \\
\hline $\begin{array}{c}\text { Scheduled } \\
\text { Castes }\end{array}$ & 66.4 & 88.1 & 47.9 \\
\hline $\begin{array}{c}\text { Scheduled } \\
\text { Tribes }\end{array}$ & 62.1 & 95.7 & 54.5 \\
\hline $\begin{array}{c}\text { Other } \\
\text { Backward } \\
\text { Classes }\end{array}$ & 56.6 & 72.8 & 43.2 \\
\hline Others & 48.9 & 59.2 & 33.7 \\
\hline INDIA & 57.0 & 74.3 & 42.5 \\
\hline
\end{tabular}

Source:[17],[19]

Among the scheduled castes and the scheduled tribes the most vulnerable are women, children and aged, those living with HIV/AIDS, mental illness and disability. These groups face severe forms of discrimination that denies them access to treatment and prevents them from achieving a better health status "Reference[17]".

Besides this it has been noted earlier that there is a strong graded connection between standard of living and all-cause mortality i.e., those in the lowest quintile of standard of living were 86 percent more likely to die as compared to those in the highest quintile of standard of living. Crucially, as standard of living goes down, mortality goes up in a systematic manner, suggesting the presence of a mortality gradient. An independent relationship was observed between social caste and mortality, with scheduled tribes having considerably higher chances of mortality as compared to the other caste. Scheduled castes also tend to have higher chances of mortality compared to the better-off caste[28]. Thus the health situation of ST's and SC's in India, which are comparatively scheduled, remotely situated, less educated, traditionally organised, materially impoverish ed and dispossessed, economically exploited and underdeveloped, disadvantaged and marginalised groups; needs a special attention. The people belonging to these casts suffer from double jeopardy. For example, 1stly they are marginalised and 2ndly the incidence of child labour among ST groups is twice as high as for upper caste children[27].

\subsubsection{Children}

Children and the elderly population face different kind of vulnerability. Chandrima Chatterjee and Gunjan Sheoran, "Reference[3]" mentions that mortality and morbidity among children are caused and compounded by poverty, their sex and caste position in society. All these have consequences on their nutrition intake, access to healthcare, environment and education. These factors directly impacts food security, education of parents and their access to correct health information and access to health care facilities. Malnutrition and chronic hunger are the important causes of death among children from poor families. Diarrhoea, acute respiratory diseases, malaria and measles are some of the main causes of death among children, most of which are either preventable or treatable with low-cost interventions. Tetanus in newborns remains a problem in at least five states: Uttar Pradesh, Madhya Pradesh, Rajasthan, West Bengal and Assam[20]. Among children the health indicators vary between the different social groups. High mortality and morbidity is reported among child ren from scheduled castes, scheduled tribes and other backward classes as compared to the general population "Reference [3]".

Infant and child mortality rates are considerably higher in rural areas than in urban areas because due to easily accessibility and better health care services in urban areas and the deprivation of rural population in terms of healthcare services. In 2001-05, the infant mortality rate was 50 percent higher in rural areas (62) than in urban areas (42). The rural-urban difference in mortality is especially large for children in the age interval 1-4 years, for whom the rate in rural areas is twice as high as the rate in urban areas. In both the neonatal and post neonatal periods, mortality in rural areas is about 50 percent higher than mortality in urban areas (see table 2).

Infant and child mortality rates have declined slightly faster in rural areas than in urban areas. Between 1991-95 
and 2001-05, infant mortality declined by 27 percent in rural areas, compared with 21 percent in urban areas. During the same period, the child mortality rate declined by 45 percent in rural areas, compared with 40 percent in urban areas. Even in the neonatal period, the decline in mortality was slightly faster in rural areas (26 percent) than in urban areas (18 percent) "Reference[17]".

Besides the health indicators the vaccination coverage is very poor among children who live in rural India. Vaccination coverage among children between 12-23 months who have received the recommended vaccines is only 39 per cent in rural India as compared to 58 per cent in urban India[21]. According to a review conducted in 2004, by the Health Ministry in collaboration with AIIMS, CDC, Atlanta, WHO, UNICEF, USAID, ICMR and other institutions, about $95 \%$ of un-im 2 munized children are concentrated in 15 States. The Southern States are much better off than the Northern States. Forty percent of the unimmunized live in Uttar Pradesh and Bihar. Uttar Pradesh has the highest number (4.6 million) of un-immunized children in the State. In spite of the fact that immunization can check disability substantially; the practice and cover has not yet been made universal. There is lack of both political will and sensitization towards it[22].

Table 2. Early childhood mortality rates

\begin{tabular}{|c|c|c|c|c|c|}
\hline \multicolumn{6}{|c|}{$\begin{array}{l}\text { Neonatal, post neonatal, infant, child, and under-five mortality rates for } \\
\text { five-year periods preceding the survey by residence, India, 2005-06. }\end{array}$} \\
\hline $\begin{array}{c}\text { Years } \\
\text { preceding } \\
\text { the } \\
\text { survey }\end{array}$ & $\begin{array}{l}\text { Neonatal } \\
\text { mortality }\end{array}$ & $\begin{array}{c}\text { Post } \\
\text { neonatal } \\
\text { mortality }\end{array}$ & $\begin{array}{l}\text { Infant } \\
\text { mortality }\end{array}$ & $\begin{array}{c}\text { Child } \\
\text { Mortality }\end{array}$ & $\begin{array}{l}\text { Under- } \\
\text { five } \\
\text { mortality }\end{array}$ \\
\hline \multicolumn{6}{|c|}{ URBAN } \\
\hline $0-4$ & 28.5 & 13.0 & 41.5 & 10.6 & 51.7 \\
\hline $5-9$ & 35.9 & 18.8 & 54.7 & 14.8 & 68.7 \\
\hline $10-14$ & 34.6 & 18.1 & 52.7 & 17.7 & 69.5 \\
\hline \multicolumn{6}{|c|}{ RURAL } \\
\hline $0-4$ & 42.5 & 19.7 & 62.2 & 21.0 & 82.0 \\
\hline $5-9$ & 53.9 & 24.2 & 78.1 & 28.7 & 104.5 \\
\hline $10-14$ & 57.5 & 28.1 & 85.5 & 38.4 & 120.6 \\
\hline \multicolumn{6}{|c|}{ TOTAL } \\
\hline $0-4$ & 39.0 & 18.0 & 57.0 & 18.4 & 74.3 \\
\hline $5-9$ & 49.3 & 22.8 & 72.2 & 25.0 & 95.4 \\
\hline $10-14$ & 51.3 & 25.3 & 76.6 & 32.3 & 106.5 \\
\hline
\end{tabular}

Source: "Referen ce[17]"

In India, children's vulnerabilities and exposure to violations of their protection rights remain spread and multiple in nature. The manifestations of these violations are various, ranging from child labour, child trafficking, to commercial sexual exploitation and many other forms of violence and abuse. With an estimated 12.6 million children engaged in hazardous occupations (2001 census), for instance, India has the largest number of child labourers under the age of 14 in the world. Those children working in the brick kilns, stone quarries, mines, carpet and zari industry suffer from occupation related diseases[23]. There is a large proportion of children in India who are living with HIV/AIDS. The most common sources of infection among children is the Mother-to-Child Transmission (MCTC), sexual abuse, blood transfusion, unsterilized syringes, including in jectable drug use "Reference[3]".

\subsubsection{Persons with Disabilities}

Disability poses greater challenges in obtaining the needed range of services. Persons with disabilities face several forms of discrimination and have reduced access to education, good health employment and other socioeconomic opportunities. In India, there is an increase of proportion of disabled population. Disability includes loco motor disability, visual, mental, speech and hearing, learning disabilities etc[22]. It has been noted that there are more than 650 million people worldwide suffering from one or another form of disability (two thirds of whom live in developing countries), most have long been neglected and marginalized by the state and society. They are victims of physical, sexual, psychological and emotional abuse, neglect, and financial exploitation, while women with disabilities are particularly exposed to forced sterilization and sexual vio lence "Re ference[6]".

Persons with disabilities face various challenges to the enjoyment of their right to health. For example, persons with physical disabilities often have difficulties accessing health care, especially in rural areas, slums and sub-urban settings; persons with psychosocial disabilities may not have access to affordable treatment through the public health system; women with disabilities may not receive gender-sensitive health services. Medical practitioners sometimes treat persons with disabilities as objects of treatment rather than rights-holders and do not always seek their free and informed consent when it comes to treatments. Such a situation is not only degrading, it is a violation of human rights under the convention on the rights of persons with disabilities (i.e., violation of Article 25 which deals with the "right to the enjoyment of the highest attainable standard of health without discrimination" for persons with disabilities and elaborates upon measures states should take to ensure this right.) and unethical conduct on the part of the medical professional these disabilities are often neither diagnosed nor treated or accommodated for, and their significance is generally overlooked "Re ference[6]". 
Table 3. Rural-Urban male and female disabilities differentials

\begin{tabular}{|c|c|c|c|c|c|c|c|c|c|c|}
\hline & \multicolumn{3}{c}{ Rural } & \multicolumn{3}{c}{ Urban } & \multicolumn{3}{c|}{ Rural + Urban } \\
\cline { 2 - 10 } Year & \multicolumn{1}{c|}{ Female } & \multicolumn{1}{c|}{ Both } & Male & Female & Both & Male & Female Both \\
\hline 1981 & & & & & & & & & 13.67 \\
\hline 1991 & 7.44 & 5.21 & 12.65 & 2.07 & 1.42 & 3.5 & 9.51 & 6.63 & 16.36 \\
\hline 2002 & 8.31 & 5.77 & 14.08 & 2.58 & 1.82 & 4.4 & 10.89 & 7.59 & 18.49 \\
\hline
\end{tabular}

Source: "Referen ce[22]".

The NSSO surveys state that over the years there has been a major increase in the disabled population of the country. In the year 1981(NSSO-37th round), there were 13.67 million disabled persons and in 1991(NSSO-47th round), this number increased to 16.36 million. According to the NSSO 58th round, the magnitude of people with one or more than one of the five-disabilities was 18.49 million in 2002. According to the NSSO 58th round in 2002, there were 18.49 million disabled persons out of which 10.89 million were males and 7.59 million were females, constituting $59 \%$ and $41 \%$ of males and females respectively. In the 47th round, in 1991 there were 16.36 million disabled persons out of which 9.51 million disabled persons were males and 6.63 million. The proportion of males and females constituted 59 and 41 percent of the disabled persons respectively (see table 3 ).

\subsubsection{Migrants}

Migration has become a major social, economic and political phenomenon, with significant human rights consequences. The international organization for migration estimates that, today, there are nearly 200 million international migrants worldwide. According to the international labour organization, 90 million of them are migrant workers. Their enjoyment of the right to health is often limited merely because they are migrants, as well as owing to other factors such as discrimination, language and cultural barriers or their legal status, social security etc[6]. India is one of the world's largest mig rant sending countries; 20 million mig rants according to World Migration Report 2005 "Reference[12]".

K. S. Jacob, $[18]$ mentions that the poor, a majority from the lower castes, migrate to different parts of the country in search of work. Their mig rant status means they lose many benefits generally offered to the poorer sections as their below poverty line and ration cards are not valid across the state borders. The migrant find it difficult to register with the National tuberculosis Programme (NTP) at their place of work, resulting in out-of-pocket expenditure for treatment, discontinuation of mediation when symptoms improve, relapse of the disease, mediation resistance and premature death. Illness and its treatment usually wipe-out all saving and are a common reason for indebtedness. Migrants are often considered vectors of communicable diseases and are not engaged by the public health system as they drive down indicators of health.

It has mentioned in the report "International Migration, Health and Human Rights",[24] that major health related problems faced by migrants - particularly undocumented migrants - with respect to their right to health:

- Migrants are generally inadequately covered by state health systems and are often unable to afford health insurance. Migrant sex workers and undocumented migrants in particular have little access to health and social services;

- Migrants have difficulties accessing information on health matters and available services. Often the information is not provided adequately by the State;

- Undocumented migrants dare not access health care for fear that health providers may denounce them to immigration authorities;

- Female domestic workers are particularly vulnerable to sexual abuse and violence;

- Migrant workers often work in unsafe and unhealthy conditions;

- Migrant workers may be more prone to risky sexual behaviour owing to their vulnerable situation, far away from their families and their exclusion from major prevention and care programmes on sexually transmitted diseases and HIV/AIDS. Their situation is therefore conducive to the rapid spread of these diseases;

- Conditions in the centres where undocumented migrants are detained may also be conducive to the spread of diseases;

- Trafficked persons are subject to physical violence and abuse, and face formidable hurdles related to their right to reproductive health (sexually transmitted diseases, including infection with HIV/AIDS, unwanted pregnancies, unsafe abortions) "Reference[24]".

\subsubsection{Aged}

In India, the population of the elderly is growing rapidly and is emerging as a serious area of concern for the government and the policy planner's. Lack of economic 
dependence has an impact on their access to food, clothing and healthcare. Among the basic needs of the elderly, medicine features as the highest unmet need. Healthcare of the elderly is a major concern for the society as ageing is often accompanied by multiple illnesses and physical ailments. Pain in the joints, followed by cough and blood pressure, piles, heart diseases, urinary problems, diabetics and cancer are the common ailments reported among elderly[25].One out of two elderly in India suffers from at least one chronic disease which requires life-long medications. Providing healthcare to elderly is a burden for especially poor households. Visual impairment, hearing problem, loco motor problem (difficulty in walking) and problems in speech are common forms of disability among elderly. Senility and neurosis is common mental illness reported among elderly[26]. Chandrima Chatterjee and Gunjan Sheoran[3], mentions that diseases like Diabetes, hypertension, tuberculosis, gastroenteritis etc are seen among migrant workers due to poverty. Internal migration of poor labourers has also been on the rise in India. The poor mig rants usually end up as casual labourers within the informal sector. This population is at high risk for diseases and faces reduced access to health services. Women and child migrants are the most vulnerable. In the case of internal migration in India, women and children mostly migrate as associated migrants with the main decision to migrate being taken by the male of the household. Many of the low/semi-skilled female migrant's work in the unorganized sector, in hazardous conditions, live in shanty arrangements and are denied access to health and healthcare. Children of poor migrant parents suffer from malnutrition and low immunizations due to their parents' perpetual lowincome uncertain jobs that necessitate frequent shifts based on concentration and are more susceptible to HIV/AIDS infection.

Chandrima Chatterjee and Gunjan Sheoran[3] further mentions that the violation of the right to health of vulnerable groups may result from direct government action, from failure of the government to fulfil its minimum core obligations and from the patterns of systematic discrimination. The specific examples

1. Imposing discriminatory practices affecting the group's health status and needs.

2. Failure to cover the eligible population with child immunization packages.

3. Failure to provide adequate obstetric and family planning services.

4. Failure to provide adequate primary healthcare, basic healthcare service to disadvantaged group.

5. Government policies and practices creating imbalances in provid ing health services, i.e., poor infrastructure in rural areas or predominantly tribal areas.

6. Systematic discrimination in access to medicines and essential drugs for particular groups, i.e., HIV/AIDS drugs, reproductive health services for particular groups like women living in poverty, in rural areas, belonging to marginalized communities.

\section{Conclusions}

Thus it can be concluded that vulnerable groups are defined as those who are subject to unfair treatment or are, relative to other age groups or sections of society, more dependent on others and therefore find it difficult to maintain their subsistence on their own and protect their rights. Besides this, certain groups in society are also subject to discriminatory treatment and feel marginalized. They need special attention to avoid exploitation. In India the wo men, children, scheduled castes and scheduled tribes, persons with disabilities, mig rants and aged are regarded as marginalised or vulnerable groups. These people are socially, economically, politically and legally ignored and excluded in Indian society. It has been seen from the data that in Indian patriarchal society the wo men's especially the rural and tribal face domestic violence, physical and sexual abuse, nutritional and psychological problems which has a profound effect upon their health status. The health status and utilisation patterns of ST's and SC's give an indication of their social exclusion as well as an idea of their linkages between poverty and health. The economically dependence, politically powerless and culturally subjugated of ST's and SC's to upper castes affects their overall lifestyle and access to food and health etc. Besides this tribal become mostly the victims of malnutrition, parasitic diseases including malaria, diarrhoea, respiratory disorders etc and genetic disorders including sickle cell anaemia thalassemia, STD, HIV AIDS and so on.

From a human right perspective, all citizens should receive adequate health, education, food and nutrition, housing, participation, equal treatment, and freedom from discrimination and violence. However these marginalised groups (STs, SCs, children, disabled and elderly) are often marginalized over looked in the public delivery system and also subject to multidimensional problems whose underlying factors are intertwined. So metimes these people have to suffer from double jeopardy.

Despite of this the rights of disabled and migrants have been violated and sometimes they are discriminated and medical personnel are not ready to treat them because they are unable to pay such a huge amount for medicines. No proper attention has been given towards their health condition. Finally it can be said that the health status of these marginalised groups are very poor as compared to other sections of population. No doubt the Indian government has framed and established the laws and rights for these marg inalised groups at different times but due to lack of proper attention towards their rights and improper implementation of their laws they have to face number of problems in Indian society. Thus there is the need of some new policy measures to make their health status good and to prevent them from discrimination and exploitation in our society. 


\section{Future Needs}

It is indeed unfortunate that a welfare state, founded on the principles of equality, social justice and democracy should display such inequities in health and access to health care. It is the 'usual suspects'- rural India, the women's, children's, the lower castes (especially the scheduled castes), the scheduled tribes, the less developed states and regions of India, that show poor health status and restricted access to healthcare. Women's health needs are numerousnutrition, general morbidity, reproductive health, disability, mental health, occupational health, - and are interrelated. Further needs are:

1. Adoption of comprehensive and gender sensitive primary healthcare to address women's diverse health needs and to overcome the many limitations that they experience in accessing healthcare.

2. Strengthen public healthcare. For the poor and the marginalised, the public sector is the only sector that can potentially provide qualified and affordable care. In the rural interiors of the country, it is usually the only sector having qualified personnel.

3. Provisions for financial support during childbirth so as to promote the health of mother social security for unorganised workers must include childcare provisions from the point of view of wo men workers.

4. Provisions aimed at ensuring protection and promotion of nutritional needs of mother and child must be included such as time breaks for nursing once the mother rejoins work.

5. Women's should be protected from domestic violence, physical and sexual abuse.

6. More and more anganwadi centres and ICDS centres should be established especially in tribal and rural areas to prevent the children's and women's from malnutrition.

7. There is a need to provide the easily accessible, affordable healthcare services for these groups to improve their health indicators.

8. The bias in the distribution of health care facilities and services between the states as well as between the rural and urban areas should be removed.

9. Social security for migrants working in the unorganised sectors is important which can help them during the time of diseases, injuries and other kinds of ailments.

10. Sexual harassment and violence at the workplace is a threat faced by all women workers. Social security for unorganised workers must ensure that complaint and redressal mechanisms against sexual harassment at the workplace following the Vishakha guidelines are put in place, keeping in mind the specific concerns of unorganised wo men workers.

11. Increase public awareness on the right to health of the vulnerable groups and engage in community education and mobilization.

12. Review the health information and services that are available to protect the health of the poor, vulnerable or otherwise disadvantaged groups, including their quality, accessibility, affo rdability and acceptability.

13. Identify disadvantaged/marginalized groups; their health status and needs in different situations.

14. Children are the future of any nation, and large number of children in the workforce at present implies fewer educated or skilled workers in the future. A high percentage of child labour also implies the loss of welfare in society, as more young children have to enter the labour market. This should be removed.

15. Identify the unmet need, particularly those resulting from adverse discrimination. Examine the curricula of medical and other health professional training schools and advocate for the inclusion of health and human rights of vulnerable groups in med ical education.

16. States should enable wo men to have control over and decide freely and responsibly on matters related to their sexuality, including their sexual and reproductive health, free from coercion, lack of information, discrimination and violence.

17. There should be proper implementation of laws regarding the health of these marginalised groups.

\section{REFERENCES}

[1] George Ritzer "The Blackwell encyclopedia of sociology", 2nd ed., Blackwell Publishing, USA, p. 2765, (2007).

[2] Online Available: httpwww.egy ankosh.ac.inbitstream123456 789349231Unit3.pdf.

[3] Chandrima Chatterjee and Gunjan Sheoran in their paper "Vulnerable groups in India" The Centre for Enquiry into Health and Allied Themes (CEHAT), Mumbai, pp. (i), 1-21, 2007.

[4] International Covenant on Civil and Political Rights (ICCPR), New York, 1996, Online Available: http://untreaty .un.org/ cod/avl/ha/iccpr/iccpr.html.

[5] The International Covenant on Economic, Social and Cultural Rights (ICESCR), Adopted and opened for signature, ratification and accession by General Assembly resolution 2200A (XXI), pp. 1-5, 1966: Online Available: http://www2.ohchr.org/en glish/law/pdf/cescr.pdf.

[6] The Right to Health, Fact sheet No. 31, WHO, USA, pp. 0719, 2008, On line Available:www.ohchr.org/Documents/Publ ications/Factsheet31.pdf.

[7] Yamin. Alicia Ely, "Learning to Dance; Advancing Women's Reproductive Health and Well-Being from the Perspectives of Public Health and Human Rights", FrancoisXavier Bagnoud Centre for Health and Human Rights, Harvard School of Public Health, Harvard Univ. Press, London, 2005.

[8] B. L. Nagda, "Demographic determinants of Tribal Health in Rajasthan", in an edited book "Health Dynamics and Marginalized communities", by Mohammad Akram, Rawat publications, pp. 135-137, India, (2007). 
[9] Pranay G. Lal and Byword, "Report of the National Commission on Macroeconomics and Health", Ministry of Health and Family Welfare, Government of India, pp. 24-25, Aug. 2005.

[10] Manasee Mishra, “Gendered vulnerabilities: women's health and access to healthcare in India", The Centre for Enquiry into Health and Allied Themes (CEHAT), India (Mumbai), pp. 1-2, 47, 2006. Also Online Available: www.cehat.org.

[11] General Recommendations, "the committee on the elimination of discrimination against women on violence against women (1992) and on women and health (1999); Online Available: http://www.un.org/womenwatch/daw/ cedaw/recommendations/recomm.htm\#recom1).

[12] Manas Jena and K. Vinaya Kumar, "Vulnerability of Dalits, Adivasis, Women, and Migrants: The need for social security", National convention on social security for unorganised workers, India, p. 5, 2010.

[13] K.R. Nayar, "Social exclusion, caste \& health: A review based on the social determinants framework", Indian Journal of Medical Research, Centre of Social Medicine \& Community Health, Jawaharlal Nehru University, India, p.355, 2007.

[14] Reproductive and Child Health- District Level Household Survey, International Institute for Population Sciences, 2002-04, Mumbai: India p. 98, 2006,

[15] Nidhi Sadana, "Dalit children in rural India: issues related to exclusion and deprivation", Indian Institute of Dalit studies, Vol. III, No.5, New Delhi, India, p. 9, 2009.

[16] B. V. Babu and Y.S. Kusuma "Tribal Health Problems; Some Social Science Perspectives" in an edited book "Health Dynamics and Marginalized communities", by Mohammad Akram, pp. 67-76, Rawat publication, India, 2007.

[17] National Family Health Survey- III (NFHS), Vol. 1, International Institute for Population Sciences, Govandi Station Road, Deonar, Mumbai - 400 088; pp. 180-182, India, 2005-2006. Online Available: http://www.nfhsindia. org.
[18] K. S. Jacob, India-caste and inequalities in health, p. 1, (2009); Online Available: http:sp oonfeedin.wordpress.com 20090822india-caste-and-inequalities-in-health.

[19] Annual Report to the people on Health, Government of India, Ministry of Health and Family Welfare, p. 06, 2010, India, Online Available: www.jeywin.com.

[20] Online Available: http://www.unicef.org/india/children.html.

[21] National Family Health Survey-III (NFHS), fact sheets, 2005-06, India, Online Available: http://www.nfhsindia.org.

[22] Leni Chaudhari, "Disability, Health and Human Rights", Centre for Enquiry into Health and Allied Themes (CEHAT), India (Mumbai), p. 4, 2006; Online Available: www.cehat. org.

[23] R.V. Angnihotram, "An overview of occupational health research in India", Indian Journal of Occupational Environment, Canada, p. 9-11, 2005.

[24] "International Migration, Health and Human Rights", WHO, Issue No. 4, (2003), Online Available: http://www.who.int.

[25] "Report on Morbidity and Treatment of Ailments", National Sample Survey Organisation (NSSO) -52nd Round, Report No. 441, Government of India, 1998.

[26] Ranjan Irudaya, "Population Aging and Health in India", Centre for Enquiry into Health and Allied Themes (CEHAT), India (Mumbai), 2006.

[27] Ankita Gandhi, Chandan Kumar, Partha Saha, Bimal Kishore Sahoo and Aishna Sharma, "India Human Development Report; Towards Social Inclusion”, Institute of Applied Manpower Research, Planning Commission, Goverment of India, Oxford, p. 14, 2011.

[28] S.V. Subramanian, Leland K. Ackerson, Malavika A. Subramanyam, and Kavita Sivaramakrishnan, "Health Inequalities in India: The Axes of Stratification", Brown journal of world affairs, Spring/Summer, Vol. xiv, issue 2, p. 130,2008 